The Internet Journal of Microbiology 2009 : Volume 6 Number 2

\title{
Antibacterial And Antifungal Activity Of Buckinghamia Celsissima Leaf Extracts
}

\author{
I.E. Cock \\ aBiomolecular and Physical Sciences \\ Genomics Research Centre \\ Griffith University \\ Southport Queensland Australia
}

Citation: I. Cock : Antibacterial And Antifungal Activity Of Buckinghamia Celsissima Leaf Extracts. The Internet Journal of Microbiology. 2009 Volume 6 Number 2

Keywords: Buckinghamia celsissima | Australian plants | antibacterial activity | medicinal plants | methanol extracts

\section{Abstract}

The antimicrobial activity of a methanolic extract of Buckinghamia celsissima leaves was investigated by disc diffusion assay against a panel of bacteria and fungi. $B$. celsissima leaf extractinhibited the growth of 5 of the 14 bacteria tested (36\%). Grampositive and Gram-negative bacteria were both affected by B. celsissima extract although Gram-positive bacteria were more susceptible. 3 of 11 Gram-negative (27\%) and 2 of the 3 Gram-positive bacteria tested (67\%) had their growth inhibited by $B$. celsissima extract. B. celsissima leaf extractdisplayed antifungal activity towards Candida albicans when tested by disc diffusion assay and inhibited the growth of the 
yeast Saccharomyces cerevisiae.The antibacterial activity of B. celsissima leaf extractwas further investigated by growth time course assays which showed significant growth inhibition in cultures of Bacilluscereus,Bacillus subtilis, Pseudomonas fluorescens and Aeromonas hydrophilia within $1 \mathrm{~h}$.

\section{Introduction}

Plants contain many biologically active compounds which have potential for development as medicinal agents. Herbal medicines already form the basis of therapeutic use in developing countries but recent years have also seen an increase in the use of herbal medications in the developed world as well. Some studies focusing on the investigation of traditional African (Kudi et al., 1999; Okeke et al., 2001), Caribbean (Chariandy et al., 1999) and Indian (Ahmad and Beg, 2001) medicinal plants have resulted in the identification of new sources of therapeutic agents. Antimicrobial multiple drug resistance toward commonly used commercial drugs has resulted in an increase in the search for antimicrobial agents from natural sources. Plant derived antimicrobial agents are a largely untapped resource with enormous medical potential and much more investigation is needed in this area.

As a result of its isolation, Australia has a variety of unique and distinctive flora not found elsewhere in the world. Australian Aborigines used a variety of plant medicines to help maintain their health prior to European settlement (Barr et al., 1993; Lassak and McCarthy, 1993). More than 150 plants from nearly 60 widely varied botanical families were used by Australian Aborigines as antiseptic agents (Lassak and McCarthy, 1993). Although there is enormous potential for the development of medicinal agents from Australian plants, much of our knowledge of the antimicrobial 
activity of Australian plants is anecdotal. Recent studies (Palombo and Semple, 2001; Cock, 2008a) have demonstrated the antibacterial activity of extracts from a number of Australian plants.

Buckinghamia celsissima (ivory curl tree) is a flowering tree of the family Proteaceae. It is endemic to the rainforests of north-eastern Australia. A recent study (Cock, 2008a) has demonstrated the antibacterial activity of methanolic extracts of $B$. celsissima extracts against a limited panel of bacteria. The current study was undertaken to validate and extend these observations against a wider panel of bacteria and fungi.

\section{Materials and Methods}

\section{Plant Collection and Extraction}

The extracts investigated in this study have been described previously (Cock, 2008a,b). Briefly, B. celsissima leaves were collected from verified trees in the suburbs of Brisbane, Australia. B. celsissima leaves were dried in a Sunbeam food dehydrator and the dried material was ground to a coarse powder. $1 \mathrm{~g}$ of each of the powdered leaves was extracted extensively in $50 \mathrm{ml}$ methanol (Ajax, AR grade) for 24 hours at 4 oC with gentle shaking. The extract was filtered through filter paper (Whatman No. 54) under vacuum followed by drying by rotary evaporation in an Eppendorf concentrator 5301. The resultant pellet was dissolved in $15 \mathrm{ml} 20 \%$ methanol. The extract was passed through $0.22 \mu \mathrm{m}$ filter (Sarstedt) and stored at $4 \mathrm{oC}$.

\section{Test Microorganisms}

All media was supplied by Oxoid Ltd. All microbial strains were obtained from Tarita Morais, Griffith University. Stock cultures of Aeromonas hydrophilia, Alcaligenes 
feacalis, Bacillus cereus, Bacillus subtilis, Citrobacter freundii, Enterobacter aerogenes, Escherichia coli, Klebsiella pneumoniae, Pseudomonas aeuroginosa, Pseudomonas fluorescens, Salmonella salford, Serratia marcescens, Staphylococcus aureus and Yersinia enterocolitia were subcultured and maintained in nutrient broth at 4 oC. Aspergillus niger, Candida albicans, and Saccharomyces cerevisiae were maintained in Sabouraud media at 4 oC.

\section{Evaluation of Antimicrobial Activity}

Antimicrobial activity of $B$. celsissima leaf extract and was determined using a modified Kirby-Bauer (Bauer et al., 1966) disc diffusion method. Briefly, $100 \mu \mathrm{l}$ of the test bacteria/fungi were grown in $10 \mathrm{ml}$ of fresh media until they reached a count of approximately 108 cells ml-1 for bacteria, or 105 cells ml-1 for fungi. $100 \mu \mathrm{l}$ of microbial suspension was spread onto agar plates corresponding to the broth in which they were maintained.

The extract was tested using $6 \mathrm{~mm}$ sterilised filter paper discs. Discs were impregnated with $10 \mu \mathrm{l}$ of the test sample, allowed to dry and placed onto inoculated plates. The plates were allowed to stand at 4 oC for 2 hours before incubation with the test microbial agents. Plates inoculated with A. feacalis, A. hydrophilia, B.cereus, B. subtilis, C. freundii, K. pneumoniae, P. aeuroginosa, P. fluorescens, S. marcescens, $Y$. enterocolitia, C. albicans and S. cerevisiae were incubated at $30 \mathrm{oC}$ for 24 hours, then the diameters of the inhibition zones were measured in millimetres. Plates inoculated with E. aerogenes, E. coli, S. Salford and S. aureus were incubated at 37 oC for 24 hours, then the diameters of the inhibition zones were measured. A. niger inoculated plates were incubated at 25 oC for 48 hours then the zones of inhibition were measured. All measurements were to the closest whole millimetre. Each antimicrobial assay was performed in at least triplicate. Mean values are reported in this report. Standard discs of ampicillin (2 $\mu \mathrm{g})$, chloramphenicol $(10 \mu \mathrm{g})$ or ciprafloxicin $(2.5 \mu \mathrm{g})$ were obtained from Oxoid Ltd. and served as positive controls for antimicrobial 
activity. For fungi, nystatin discs (100 $\mu \mathrm{g}$, Oxoid Ltd.) were used as a positive control. Filter discs impregnated with $10 \mu \mathrm{l}$ of distilled water were used as a negative control.

\section{Bacterial Growth Time Course Assay}

$3 \mathrm{ml}$ of bacterial cultures (B. cereus, B. subtilis, A. hydrophilia, $P$. fluorescens) in nutrient broth were $27 \mathrm{ml}$ nutrient broth containing $0.5 \mathrm{ml} \mathrm{B.} \mathrm{celsissima} \mathrm{extract}$ (diluted 1 in 10 in sterile deionised water) were incubated at 30 oC with gentle shaking. The optical density was measured at $550 \mathrm{~nm}$ after $0,1,2,4$ and $6 \mathrm{~h}$ incubations. Control tubes were incubated under the same conditions but without the extract. All assays were performed in triplicate.

\section{Results and Discussion}

B. celsissima leaf extract was diluted to a $26.3 \mathrm{mg} / \mathrm{ml}$ concentration. $10 \mu \mathrm{l}$ of the extract was tested in the disc diffusion assay against 17 microorganisms (table 1). The B. celsissima leaf extract inhibited the growth of 5 of the 14 bacteria tested (36\%). The antibacterial activity was strongest against the Gram-positive bacteria $B$. cereus and B. subtilise (as determined by the diameter of the zone of inhibition).

Table 1: Antibacterial activity of B. celsissima extract. Numbers indicate the mean diameters of inhibition of triplicate experiments \pm standard deviation. - indicates no growth inhibition. Chl indicates chloramphenicol $(10 \mu \mathrm{g})$ was used as the positive control. Amp indicates ampicillin ( $2 \mu \mathrm{g})$ was used as the positive control. Cip indicates ciprafloxicin ( $2.5 \mu \mathrm{g})$ was used as the positive control. Nys indicates nystatin discs $(100 \mu \mathrm{g})$ were used as the positive control 
Both Gram-positive and Gram-negative bacterial growth were inhibited by $B$. celsissima leaf extract although a greater susceptibility of Gram-positive bacteria was apparent. Of the 11 Gram-negative bacteria tested, 3 (27\%) were inhibited by $B$. celsissima extract. The B. celsissima leaf extract inhibited the growth of 2 of the 3 Gram-positive bacteria tested (67\%). A greater susceptibility of Gram-positive bacteria has been previously reported for South American (Paz et al., 1995), African (Kudi et al., 1999; Vlietinck et al., 1995) and Australian (Palombo and Semple, 2001) plant extracts. Susceptibility differences between Gram-positive and Gram-negative bacteria may be due to cell wall structural differences between these classes of bacteria. The Gram-negative bacterial cell wall outer membrane appears to act as a barrier to many substances including antibiotics (Tortora et al., 2001).

B. celsissima leaf extract also demonstrated limited antifungal activity. The extract inhibited the growth of $C$. albicans. However, the antifungal activity was not particularly strong (as determined by the zone of inhibition) compared to the nystatin control. B. celsissima leaf extract also inhibited the growth of the yeast S. cerevisiae.

The antibacterial activity of the B. celsissima leaf extract was further investigated by bacterial growth time course assays in the presence and absence of the extract. The concentration of the extract used in these assays was $43.8 \mu \mathrm{g} / \mathrm{ml}$. B. celsissima leaf extract was able to significantly inhibit B. cereus (figure 1a), B. subtilis (figure 1b), Pseudomonas fluorescens (figure 1c) and A. hydrophilia (figure 1d) growth within $1 \mathrm{~h}$ indicating a rapid antimicrobial action.

Figure 1: Inhibition of bacterial growth by methanolic extract of $B$. celsissima leaves against (a) B.cereus, (b) B.subtilis, (c) P.fluorescens, (d) A. hydrophilia. represent measured bacterial growth values for test $\leq$ For all graphs, represent control bacterial growth values'cultures (with extract) and (no extract). Values are the mean of triplicate determinations. 
Interestingly, growth of $P$. fluorescens was not seen to be inhibited in the disc diffusion assays (table 1). The extract may inhibit/slow bacterial growth without completely killing all bacteria in the culture. As shown in figure 1c, P. fluorescens growth has been partially inhibited by the $B$. celsissima extract. Although $P$. fluorescens growth did not attained the same level as the control by the end of the $6 \mathrm{~h}$ incubation, it is approaching this level and would be expected to increase to the control levels given further time. P. fluorescens growth may have been evident in the disc diffusion assays because of the longer incubation time ( $24 \mathrm{~h}$ ) required for these assays. Therefore, disc diffusion assays alone may not detect some antimicrobial agents with lower efficiacies because of the incubation time required.

The findings of this study have established the susceptibilities of a range of microbes to B. celsissima leaf extract. Both Gram-positive and Gram-negative were susceptible to $B$. celsissima leaf extract. The range of microbial susceptibilities indicates the potential of $B$. celsissima leaf extract as a surface disinfectant as well as for medicinal purposes and as food additives to inhibit spoilage. However, further studies are needed before these extracts can be applied to these purposes. In particular, toxicity studies are needed to determine the suitability of these extracts for these use as antiseptic agents and as a food additive. One previous study (Setzer et al., 2001) reported no toxicity of low concentrations of B. celsissima bark extract towards HepG2 and two carcinoma cell lines. Studies within this laboratory (Cock, 2008b) have shown B. celsissima leaf extracts to be non-toxic towards brine shrimp. No data was available for the toxicity of leaf extracts towards human cell lines. Further studies are needed to determine the toxicity of $B$. celsissima leaf components before their use as antimicrobial agents.

\section{Aknowledgements}

Financial support for this work was provided by the School of Biomolecular and Physical Sciences, Griffith University, Australia. 


\section{Correspondence to}

Tel.: $\quad$ +61737357637 ; fax: +61 $\quad$ +61355282.

E-mail address: I.Cock@griffith.edu.au (I. E. Cock).

\section{References}

Ahmad, I and Beg, AZ, 2001. Antimicrobial and phytochemical studies on 45 Indian medicinal plants against multi-drug resistant human pathogens Journal of Ethnopharmacology, 74, 113-123. (ㅁ)

Barr, A, Chapman, J, Smith, N, Wightman, G, Knight, T, Mills, L, Andrews, M, Alexander, V, 1993. Traditional Medicines in the Northern Territory or Australia by Aboriginal communities of the Northern Territory. Conservation Commission of the Northern Territory, Darwin. (ㅁ)

Bauer, AW, Kirby, WM, Sherris, JC and Turck, M, 1966. Antibiotic susceptibility testing by a standardized single disk method. American Journal of Clinical Pathology, 45, 493-496. (ㅁ)

Chiariandy, CM, Seaforth, CE, Phelps, RH, Pollard, GV and Khambay, BP, 1999. Screening of medicinal plants from Trinidad and Tobago for antimicrobial and insecticidal properties. Journal of Ethnopharmacology, 64, 265-270. (ㅇ)

Cock, IE, 2008a, Antibacterial activity of selected Australian native plant extracts, The Internet Journal of Microbiology, 4, 2. (ㅁ)

Cock IE, 2008b, Assessment of the toxicity of selected Australian native plant extracts using the Artemia franciscana nauplii bioassay, The Internet Journal of Toxicology, Volume 5, Number 2. ()ㅡ 
Kudi, AC, Uhoh, JU, Eduvie, LO and Gefu, J, 1999. Screening of some Nigerian medicinal plants for antibacterial activity. Journal of Ethnopharmacology, 67, 225228. (

Lassak EV, McCarthy T, 2006, Australian Medicinal Plants, Reed publishers,

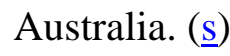

Okeke, MI, Iroegbu, CU, Eze, EN, Okoli, AS, Esimone, CO, 2001. Evaluation of extracts of the root of Landolphia owerrience for antibacterial activity. Journal of Ethnopharmacology, 78, 119-127. (ㅁ)

Paz, EA, Cerdeiras, MP, Fernandez, J, Ferreira, F, Moyna, P, Soubes, M, Vazquez, A, Vero, S and Zunino, L, 1995. Screening of Uruguayan medicinal plants for antimicrobial activity. Journal of Ethnopharmacology, 45, 67-70. (ㅁ)

Palombo, EA and Semple SJ, 2001. Antibacterial activity of traditional Australian medicinal plants. Journal of Ethnopharmacology, 77, 151-157. (ㅁ)

Setzer, MC, Setzer, WN, Jackes, BR, Gentry, GA and Moriarity, DM, 2001. The medicinal value of tropical rainforest plants from Paluma, North Queensland, Australia. Pharmaceutical Biology, 39, 1, 67-78. (ㅁ)

Tortora, GJ, Funke, BR and Case, CL, 2001. Microbiology: An Introduction. Benjamin Cummings, San Francisco. (ㅁ)

Vlietinck, AJ, van Hoof, L, Totte, J, Lasure, A, Vanden Berghe, D, Rwangabo, PC, and Mvukiyumwani, J, 1995. Screening of a hundred Rwandese medicinal plants for antimicrobial and antiviral properties. Journal of Ethnopharmacology, 46, 31-47. (ㅁ)

This article was last modified on Tue, 28 Jul 09 19:49:24 -0500

This page was generated on Sun, 06 Sep 09 21:06:42 -0500, and may be cached. 